\title{
Structural and Techno-Functional Properties of Cassava Starches and Application on Cheese Bread
}

\author{
Ronei Dariva ${ }^{1(\mathbb{D}}$, Rosicler Colet ${ }^{1(\mathbb{D})}$, Alexandra Manzoli ${ }^{1(\mathbb{D})}$, Ilizandra Aparecida Fernandes ${ }^{1(\mathbb{D})}$, \\ Guilherme de Souza Hassemer ${ }^{1}$ (D), Rogério Luis Cansian ${ }^{1}$ (D), Geciane Toniazzo Backes ${ }^{1(D)}$, Eunice \\ Valduga $1, *$ (iD) \\ 1 Department of Food Engineering, URI -Erechim Av. Sete de Setembro, 1621, Erechim, Rio Grande do Sul, Brazil, 99709 - \\ 910, Brazil \\ * Correspondence: veunice@ uricer.edu.br;
}

Scopus Author ID 23490413300

Received: 20.05.2020; Revised: 10.06.2020; Accepted: 12.06.2020; Published: 16.06.2020

\begin{abstract}
This study aims to evaluate the structural and techno-functional properties of native and modified cassava starches, focusing on the production of frozen cheese bun formulations. The structural and techno-functional properties of cassava starches, both native and modified, were evaluated via thermogravimetric analysis (TGA), scanning electron microscopy (SEM), energy-dispersive X-ray spectroscopy (EDX), X-ray diffraction (XRD), baking properties, as well as, resistance to freezing and thawing cycles. The native sample containing $17 \%$ of amylose had the highest expansion rate among the tested starches. In contrast, pre-gelatinized acetylated starches showed little expansion capacity. The starch samples displayed resistance to up to 2 freezing and thawing cycles. The XRD analysis showed that native and modified starches had high crystallinity and similar diffraction patterns. SEM images revealed that modified starches possess smaller particles (32 to $52 \mu \mathrm{m}$ ) with a greater surface area when compared to the native samples. Modified samples also displayed surface indentations, which would explain their greater water absorption potential. TGA analysis has shown a reduction $(\mathrm{P}<0.05)$ in the modified starches thermal stability. These data are relevant technological advancement of the cheese bun industry since choosing adequate starch is crucial to ensure the final product's quality in large scale industrial production.
\end{abstract}

Keywords: Starch; thermal properties; scanning electron microscopy; energy-dispersive X-ray spectroscopy; X-ray diffraction; cheese bread.

(C) 2020 by the authors. This article is an open-access article distributed under the terms and conditions of the Creative Commons Attribution (CC BY) license (https://creativecommons.org/licenses/by/4.0/).

\section{Introduction}

Starch is composed of two fractions: amylose, which is made up of essentially $\alpha-(1 \rightarrow 4)$ D-glucopyranosyl units and amylopectin, which is made up of a large number of short chains linked together at their reducing end side by an $\alpha-(1 \rightarrow 6)$ linkage [1,2]. Starch is able to affect the texture, viscosity, gel formation, adhesion, binding, moisture retention, film formation, and homogeneity of a product. Non-food applications of starch include pharmaceuticals, textiles, alcohol-based fuels, and adhesives. Starch has also found a new place in the production of lowcalorie substitutes, biodegradable packaging materials, thin films, and thermoplastic materials with improved thermal and mechanical properties [3].

Commercially available starches and their derivatives are classified as cereal starch or as tuberous or root starch [4,5], and cassava (Manihot esculenta Crantz; Euphorbiaceae) is one of the major staple food crop s in many countries worldwide [6]. Cassava sour starch is 
produced in Latin America, particularly in Brazil, Colombia, and Paraguay and is considered one of the staples of these countries' traditional rural industries. This kind of starch is used in the production of industrially processed snacks, and to make cheese buns such as pandebono and pan de yuca (Colombia), and "pão de queijo" (Brazil). These baked buns do not go through a yeast fermentation like wheat-based bread. In the case of cheese buns, the dough is baked immediately after kneading, with this being considered a very attractive feature, mainly in the market of gluten-free baked goods [7]. The starch market has been growing and improving in recent years, leading to the search for products with specific characteristics that meet the industry's requirements. The production of modified starches is an alternative that has been developed with the objective of overcoming one or more limitations that regular or native starches have, and thus, increase the polymer's usefulness. According to official data, the modified starch market is expected to grow $4.1 \%$ per year and is expected to be worth USD 12.14 billion up to 2022 [8], indicating the high demand for these ingredients.

The chemical, physical, enzymatic, and genetic modification of starch has been most promising, with a large number of new techniques. Osmotic-pressure treatment, multiple deep freezing, and thawing, as well as ozone-oxidized [3] and microwave-assisted [9], are capable of producing a variety of modified starches with numerous properties to be applied in the food industry. The modification process can increase the starch's resistance to continuous cycles of freezing and thawing, shear strength, increase stability at high temperatures, increase yields, improve gel characteristics (texture and consistency), and solubility in cold water, and reduce downgrading [3,7,10-14].

During the production of cheese buns, it is difficult to define what rheological characteristics the starch must possess, in order to maintain the dough's and, consequently, the bun's quality. In this context, this study seeks to evaluate the structural and techno-functional properties of native and modified cassava starches, via thermogravimetric analysis, scanning electron microscopy, energy-dispersive X-ray spectroscopy, X-ray diffraction, baking property and resistance to freezing and freezing and thawing cycles, focusing on their potential application in the production of frozen cheese bun formulations.

\section{Materials and Methods}

\subsection{Samples.}

Commercial samples of native cassava starches (Cassava starch 1 - CS1, 17\% of amylose - Podium, Cabo de Santo Agostinho, PE, Brazil; Cassava starch 2 - CS2, 15\% of amylose - O'linda, Nova Londrina, PR, Brazil), and modified cassava starches, obtained by acetylation and pre-gelatinized (Modified starch 1 - MS1, 11\% of amylose - Ingredion, National Starch, Tamboara, PR, Brazil; Modified starch 2 - MS2, 9\% of amylose - Ingredion, National Starch, Tamboara, PR, Brazil; Modified starch 3 - MS3, 12\% of amylose - Podium, Cabo de Santo Agostinho, PE, Brazil) were characterized in terms of structural and technofunctional properties and subsequently used to produce different formulations of cheese buns.

\subsection{Native and modified cassava starches structural properties.}

\subsubsection{Scanning electron microscopy (SEM).}

The morphology of the starches, both native as well as modified, were analyzed by scanning electron microscopy (SEM) technique using a JSM6510/JEOL model microscope 
(JEOL instrument, Austin, EUA). The samples were mounted on SEM stubs with double-sided adhesive tape and coated with an approximate $20 \mathrm{~nm}$ gold layer using an SCD 0050/LEICA metallizer (LEICA instrument, California, EUA). Particle size was measured by the Size Meter software (version 1.1) using at least 50 particles for each experiment, while the software Statistica ${ }^{\circledR} 5.0$ was used to calculate the particle size distribution.

\subsubsection{Energy-dispersive X-ray spectroscopy (EDX).}

The chemical composition qualitative analysis of the starch samples was done using energy-dispersive X-ray spectroscopy (EDX) with a 6742A/Thermo-Scientific equipment attached to the JSM6510/JEOL scanning electron microscope. In addition, XPS mapping approach was used to study chemical elements dispersion on the surface of the sample.

\subsubsection{X-ray diffraction $(\mathrm{XRD})$.}

The characterization of the starches' physical structure (crystalline and/or amorphous) was performed via X-ray diffraction (XRD) using a Shimadzu XRD6000 diffractometer (Shimadzu, Kyoto, Japan) with CuKa radiation, from $10^{\circ}$ to $80^{\circ}(2 \theta)$ at $2^{\circ} \mathrm{min}^{-1}$.

\subsubsection{Thermogravimetric analysis (TGA).}

Thermal analysis (TGA) of the different starch samples were performed in a TA Q500 thermal analyzer (TA Instruments, New Castle, DE) with a synthetic air atmosphere and $60 \mathrm{~mL} / \mathrm{cm}$ flow rate. Samples were heated from room temperature to $600^{\circ} \mathrm{C}$ with a heating rate of $10^{\circ} \mathrm{C} / \mathrm{min}$.

\subsection{Techno-functional characteristics of native and modified starches.}

\subsubsection{Baking properties of starches.}

The baking properties of the starches were measured by weighing $12 \mathrm{~g}$ of starch sample and partially cooking it by adding $10 \mathrm{~mL}$ of boiling deionized water. This partially cooked starch was homogenized to produce a dough that was then molded into three small balls and baked on an electric oven (Turbogas V200 LIEME, São Paulo, Brazil) at $200^{\circ} \mathrm{C}$ for 25 min. After baking, the doughs were weighed and made impermeable by using paraffin, with their volumes determined by dropping the samples into graduated cylinders and measuring the volume of water displaced. The expansion rate was obtained by dividing volume by weight and was expressed as a specific volume $(\mathrm{mL} / \mathrm{g})[15]$.

\subsubsection{Resistance to freezing and freeze-thaw cycles of starches.}

The starch samples were diluted in deionized water in a proportion of $8 \%$, gelatinized, kept in boiling water, and shaken for $10 \mathrm{~min}$. The gel was divided into three $50 \mathrm{~g}$ portions, stored in plastic packages and frozen $\left(-18^{\circ} \mathrm{C}\right)$. The samples were submitted to three freezing cycles, each lasting $72 \mathrm{~h}$. The first, second, and third cycles samples were frozen at $-18^{\circ} \mathrm{C}$ and thawed at $45^{\circ} \mathrm{C}$ for $3 \mathrm{~h} \mathrm{[16].}$ 


\subsection{Statistical treatment.}

The results $(n=3)$ were statistically treated by analysis of variance (ANOVA), followed by the averages differences comparison by the Tukey test, with a $95 \%$ confidence level, using the Statistic software 7.0 version.

\section{Results and Discussion}

\subsection{Cassava starches structural properties.}

Each starch granule is a semi-crystalline system, consisting of crystalline and amorphous regions. The characteristics of the different crystalline structures present in the starch granules have been widely studied via X-ray diffraction (XRD). Figure 1 shows the diffraction patterns for modified (A, B, and C) and native (D) cassava starches.
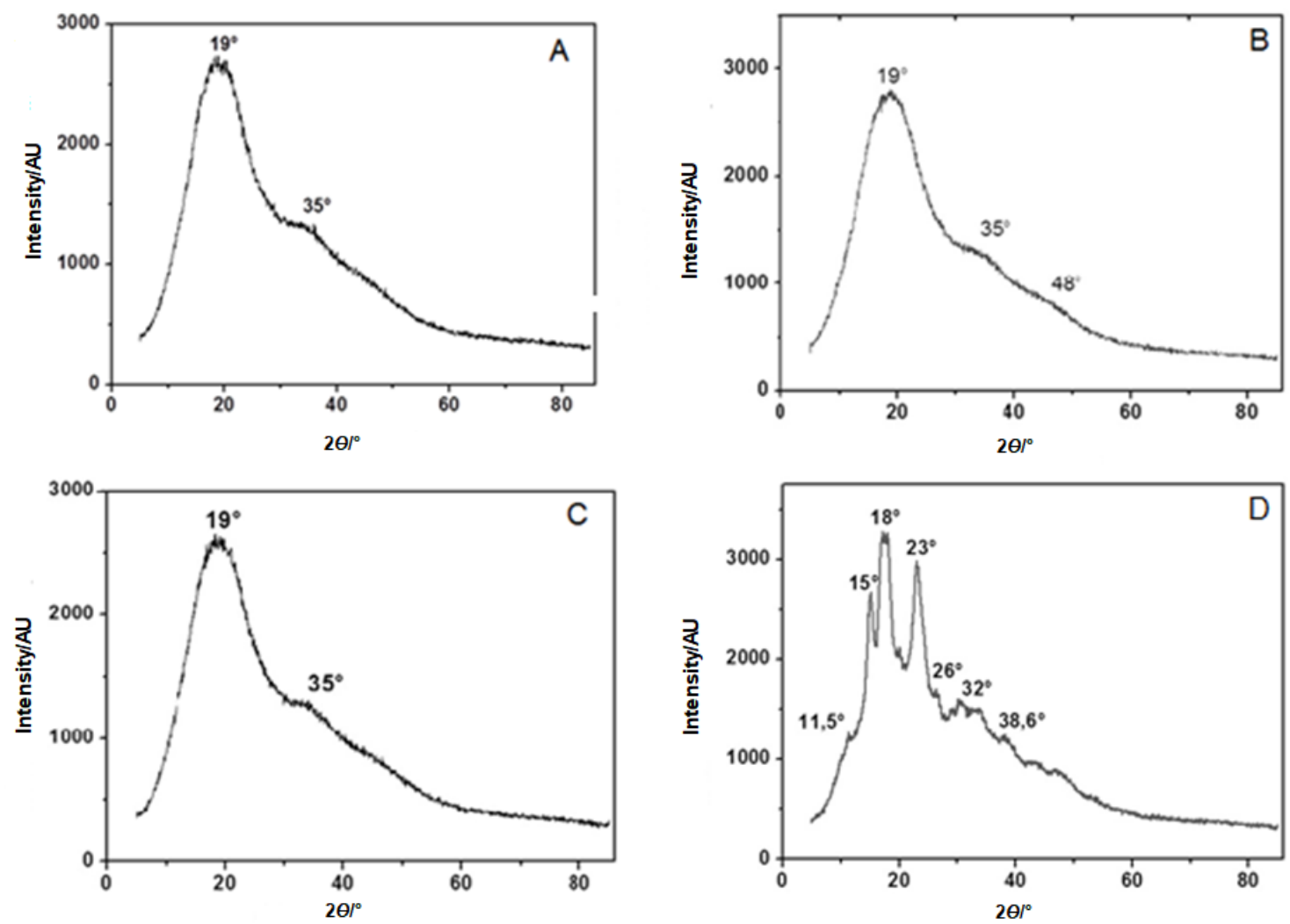

Figure 1. X-ray diffraction patterns of MS1 (A), MS2 (B), and MS3 (C) pre-gelatinized acetylated modified cassava starches and CS1 and CS2 (D) native starches.

Starches generally have a crystalline nature attributed to the organization of the amylopectin molecules within the granule. The starch can be classified according to its diffraction pattern informs $\mathrm{A}, \mathrm{B}$, and $\mathrm{C}$, of which $\mathrm{A}$ and $\mathrm{B}$ are present in cereals and form $\mathrm{C}$, considered as a mixture of the above with predominance of $\mathrm{A}$, is found in the majority of tubers, legumes, and seeds, where cassava starches are included [17].

The diffraction patterns presented in Figure 1 for the modified starches (MS1, MS2, and MS3) were similar, with a stronger peak in $2 \theta$ at $19^{\circ}$, and a peak of lower intensity at $35^{\circ}$. MS2 (Figure 1B) also showed a low-intensity peak at $48^{\circ}$. The peaks intensity for the 3 modified starches was homogeneous, and no difference in crystallinity among the modified starches could be distinguished. 
The diffraction pattern for native cassava starch showed peaks in $2 \theta$ at approximately $11.5^{\circ}, 15^{\circ}, 18^{\circ}, 23^{\circ}, 26^{\circ}, 32^{\circ}$ and $38.6^{\circ}$ (Figure 1D), indicating a C-type crystallinity pattern [18]. Schlemmer et al. [19] found diffraction patterns $\left(2 \theta \sim 15^{\circ}\right)$ and $B\left(2 \theta \sim 17^{\circ}\right.$ and $\left.23^{\circ}\right)$ values for starch films. Also, they described this diffraction pattern as being type $\mathrm{C}$, corroborating with the present study's results.

The native starches granules (CS1, Figure 2D) and (CS2, Figure 2E) displayed particles with spherical, oval, and oval-truncated shapes, with linear or star hilum occupying the center of the grain, in accordance to Monroy et al. [18] and Leonel [20]. The particles of these two starch samples (CS1 and CS2) are well grouped, with clusters formed by tens of granules. The native cassava starch particles diameter for the CS1 and CS2 samples ranged from 3.8 to $23.7 \mu \mathrm{m}(15.2 \mu \mathrm{m}$ average) and from 3.2 to $25 \mu \mathrm{m}$ (18.4 $\mu \mathrm{m}$ average), respectively. The diameter values were similar to those reported by Defloor et al. [21] from 3 to $32 \mu \mathrm{m}$, by Leonel [20] between 15 to $20 \mu \mathrm{m}$ and by Cereda et al. [22] of $20 \mu \mathrm{m}$.
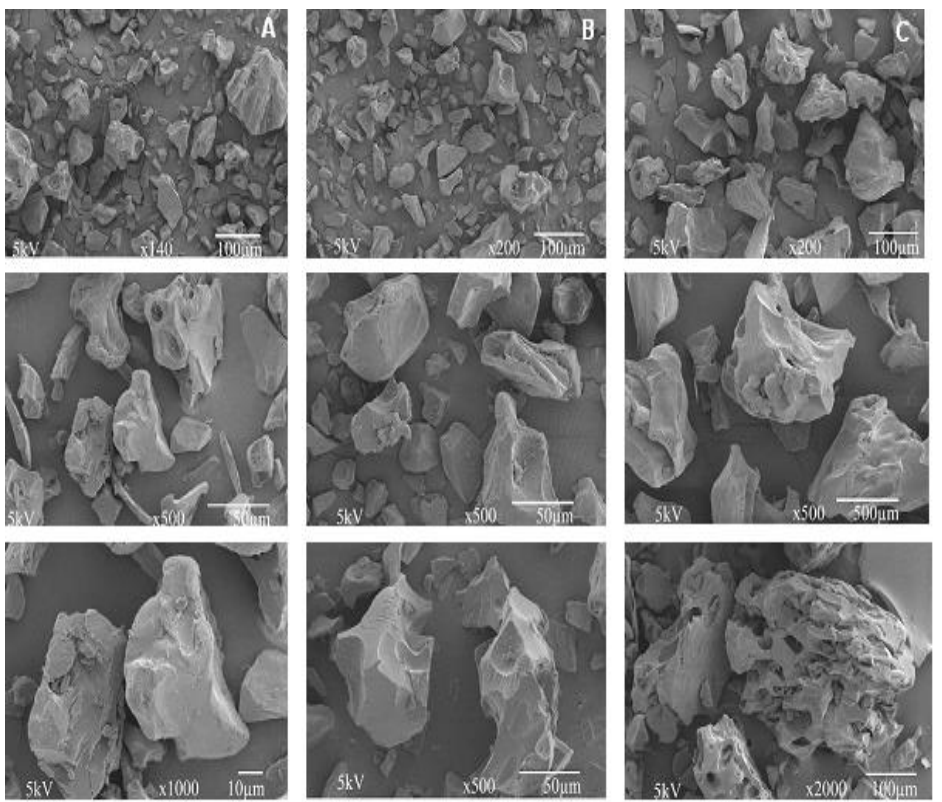
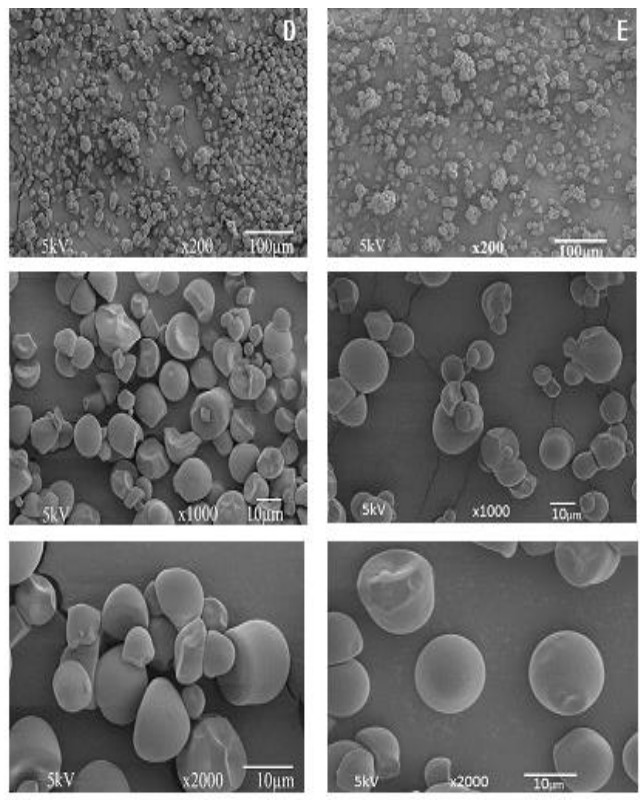

Figure 2. SEM images of MS1 (A), MS2 (B), and MS3 (C) pre-gelatinized acetylated cassava modified starches and CS1(D) and CS2 (E) native cassava starches.

For three modified starches, the SEM images (Figure 2A, 2B and 2C) showed similar particles with fragmented granules showing indentations on the surface and sizes varying from 1.7 to $63 \mu \mathrm{m}$ ( $32 \mu \mathrm{m}$ average) for the MS1 sample, from 1.4 to $167 \mu \mathrm{m}$ (48 $\mu \mathrm{m}$ average) for the sample MS2 and 2.7 to $184 \mu \mathrm{m}(51.74 \mu \mathrm{m}$ average) for the MS3 sample. These characteristics are probably caused by the acetylation and pre-gelatinization processes.

The smaller diameter particles found in the modified starches $(<1.4 \mu \mathrm{m})$ are suspended in air, causing fog when the starch is transferred from one place to another, as well as providing an increase in the contact surface and water absorption, something which is very beneficial in the case of cheese bun dough. In addition, the indentations found in the surface of the granules facilitate water permeation, leading to an increased capacity of water absorption at lower temperatures when compared to the native starches.

These structural analyses made it possible to understand the effects of the acetylation and pre-gelatinization processes in cassava starches since there is a lack of scientific work in this area. 
The Energy-dispersive X-ray spectroscopy (EDX) technique allows for the investigation of the chemical elements found in several sample types. Its characterization capacity is related, in large part, to the unique atomic structure of each element, so that the emitted X-rays, identify specific elements, thus allowing a punctual chemical analysis of the sample constituents [23]. The dispersive energy spectroscopy (EDX) images for the modified starches (Figure 3A, 3B, and 3C) showed that carbon and oxygen were the main constituents. Sodium, chlorine, and calcium elements were found in the three modified starches, whereas silicon was present in MS1 and MS3 samples. These differences are caused by factors such as planting, soil, climate, and harvesting process, as well as the particularities regarding the methods used in order to obtain different pre-gelatinized acetylated modified starches. For two native cassava starches, the dispersive energy spectroscopy (EDX) images showed similarity to the constituent elements of the starches, with carbon, oxygen, sodium, silicon, and calcium is present. Carbon and oxygen were the main constituents of these samples (Figure 3D).
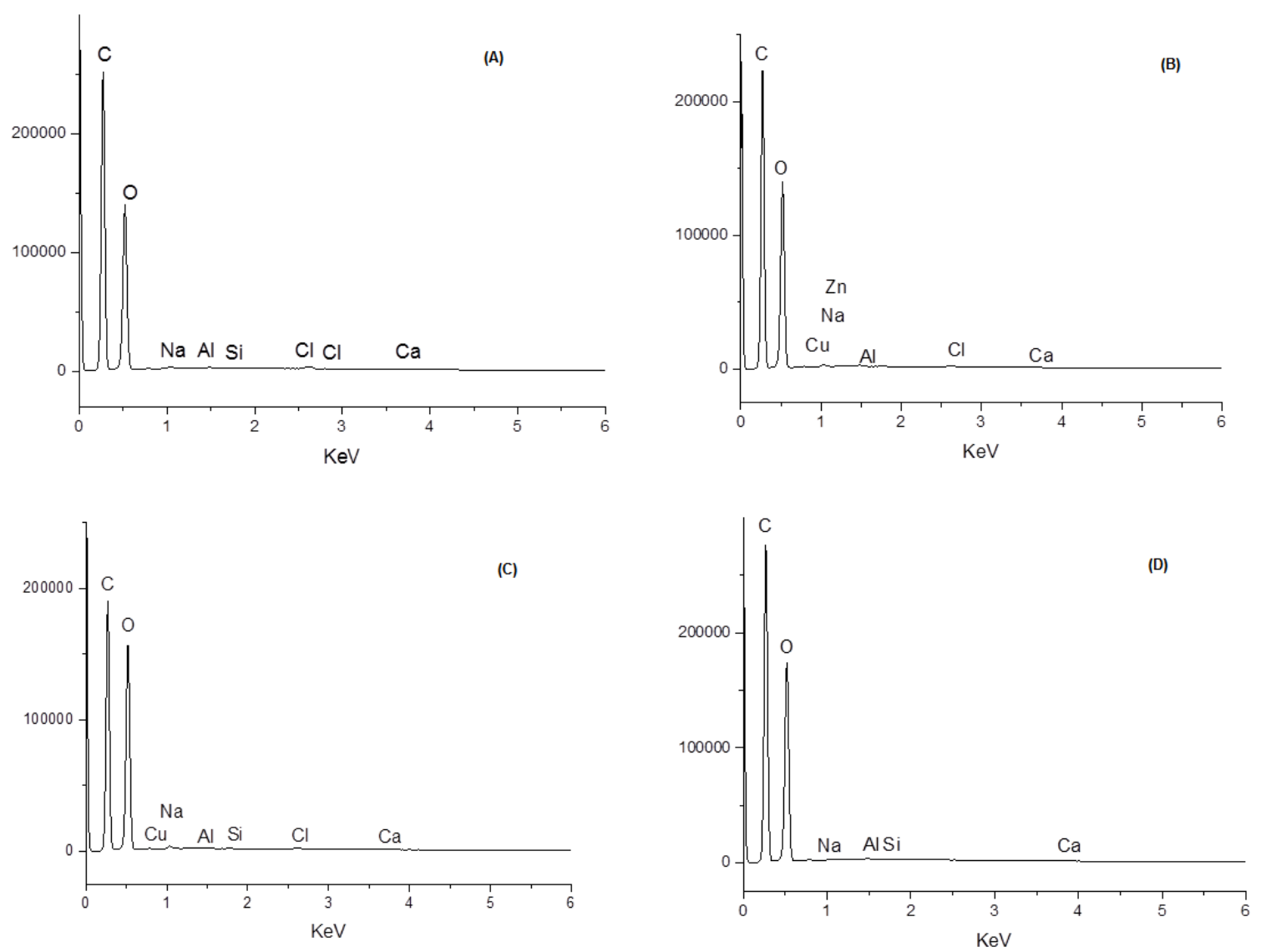

Figure 3. Survey spectra for pre-gelatinized acetylated modified starches surface MS1 (A), MS2 (B) and MS3 (C) and native starch surface CS (D).

The TG curves for both modified starches and native starches (Figure 4) showed three stages of mass loss, with the first one $\left(25-110^{\circ} \mathrm{C}\right)$, characterizing an endothermic peak, related to the moisture loss and the starch' dehydration, while the other two were attributed to amylose and amylopectin thermal decomposition. For the first exothermic event $\left(250-350^{\circ} \mathrm{C}\right)$, the highest mass loss in the order of $70 \%$ due to starch degradation and, the second exothermic event $\left(400-500^{\circ} \mathrm{C}\right)$ was attributed to the oxidation of partially decomposed organic material, which was caused by synthetic air flowing through the system.

These results are similar to those reported by Guinesi et al. [24]. They observed three events in the thermogravimetric analysis of cassava starch, with mass loss and dehydration in 
the first stage, followed by two stages of decomposition. The degradation curves (TGA) using a nitrogen atmosphere, $20 \mathrm{~mL} / \mathrm{min}$ flow rate, and $20^{\circ} \mathrm{C} / \mathrm{min}$ heating rate showed a second mass loss of $66.8 \%$ for cassava starch between $308-374^{\circ} \mathrm{C}$.

The TGA results indicated that the starch modification processes caused a reduction in the water amount in sample MS1 (Figure 4A) and sample MS2 (Figure 4B), but not in sample MS3 (Figure 4C). The two samples of native starch presented a considerable difference to the amount of water, with 11 and 5.1\% of moisture for CS1 and CS2 starches, respectively. These values are directly related to the starch's ability to retain water during dough production, contributing directly to the viscosity of the cheese bun dough, in this case. A significant reduction in the thermal stability (Tonset) of the MS2 and MS3 modified starch samples (Table 1) was observed when compared to the native starches, which is mainly associated with the sample's chemical composition and the modification processes.
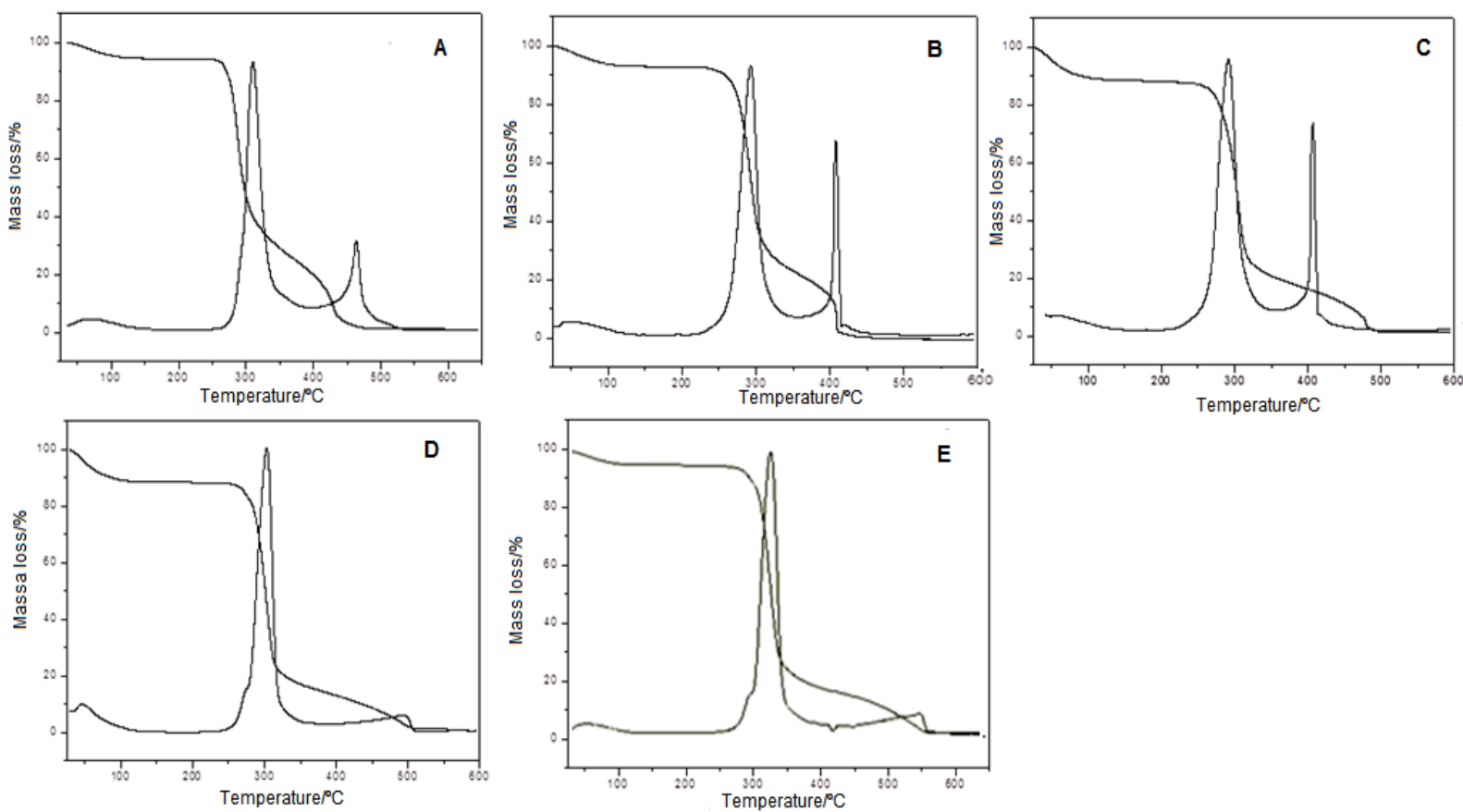

Figure 4. TGA thermograms for the modified starches MS1 (A), MS2 (B) and MS3 (C) and the native starches CS1 (D) and CS2 (E) obtained under the air atmosphere at a heating rate of $10^{\circ} \mathrm{C} / \mathrm{min}$.

Table 1. Thermal properties (thermogravimetric analysis) of the modified and native starches.

\begin{tabular}{|c|c|c|c|c|}
\hline Starches & Moisture (\%)* & $\mathbf{T}_{\text {onset }}\left({ }^{\circ} \mathbf{C}\right)^{* *}$ & $\mathbf{T}_{\max }\left({ }^{\circ} \mathbf{C}\right)^{* * *}$ & Residues at $600^{\circ} \mathrm{C}(\%)$ \\
\hline MS1 & 4.73 & 262 & 310 & 1.2 \\
\hline MS2 & 6.5 & 246 & 292 & 0.3 \\
\hline MS3 & 10.8 & 247 & 292 & 1.5 \\
\hline CS1 & 11.0 & 263 & 303 & 0.5 \\
\hline $\mathrm{CS} 2$ & 5.1 & 270 & 305 & 0.1 \\
\hline
\end{tabular}

${ }^{*}$ Mass loss at $105^{\circ} \mathrm{C}$;

** temperature where $2 \%$ mass loss occurs after $105^{\circ} \mathrm{C}$;

${ }^{* * *}$ temperature of the first thermal decomposition peak.

The MS1 modified starch sample displayed very similar thermal stability to native starch samples. The residue content (ash content) at $600^{\circ} \mathrm{C}$, a temperature associated with the last decomposition step, showed different values, with no correlation found between the samples. This could be related to the last decomposition step since due to its intensity may cause fluctuations on the ash content. Lawal [25] attributed the starch granules disintegration at high temperatures with the breakdown of some amylopectin bonds. According to Aggarwall 
et al. [26], heat treatment in starches usually leads to its depolymerization when the applied temperature exceeds $300^{\circ} \mathrm{C}$.

\subsection{Techno-functional characteristics of starches and cheese bun formulations.}

The native and modified starches presented significant differences $(\mathrm{P}<0.05)$ for the expansion index (Table 2), and the native starches CS1 and CS2 presented the highest specific volumes of 7.5 and $6.7 \mathrm{~cm}^{3} / \mathrm{g}$, respectively.

Modified starch MS1 has the largest expansion capacity $\left(4.3 \mathrm{~cm}^{3} / \mathrm{g}\right)$, approximately 1.5 times higher than other modified starches (Table 2). This is probably due to the smaller particle size of this starch (from 1.7 to $63 \mu \mathrm{m}$ and $32 \mu \mathrm{m}$ average), resulting from the modification process. The modified starches displayed little expansion potential, but a large capacity to absorb water to form more compact and viscous gels. The opposite, however, was observed in the samples of native starches. Thus, buns made using only native cassava starch tend to be more compact since there is less water available to be transformed into steam.

Table 2. Baking property and loss of water of starches.

\begin{tabular}{l|l|l|l|l}
\hline \multirow{2}{*}{ Starches } & \multirow{2}{*}{$\begin{array}{l}\text { Specific volume } \\
\end{array}$} & \multicolumn{4}{|l}{ Loss of water $\mathbf{( \% )}$} & \\
\cline { 3 - 5 } & $\left.\mathbf{c m}^{\mathbf{3}} \mathbf{g}\right)$ & $\mathbf{1}^{\text {st }}$ cycle & $\mathbf{2}^{\text {nd }}$ cycle & $\mathbf{3}^{\text {rd }}$ cycle \\
\hline MS1 & $4.3^{\mathrm{c}} \pm 0.18$ & $0^{\mathrm{a}}$ & $0^{\mathrm{c}}$ & $6.4^{\mathrm{c}} \pm 0.58$ \\
\hline MS2 & $2.8^{\mathrm{d}} \pm 0.12$ & $0^{\mathrm{a}}$ & $0^{\mathrm{c}}$ & $0^{\mathrm{c}}$ \\
\hline MS3 & $2.3^{\mathrm{d}} \pm 0.22$ & $0^{\mathrm{a}}$ & $2.7^{\mathrm{b}} \pm 0.58$ & $7.2^{\mathrm{c}} \pm 2.5$ \\
\hline CS1 & $7.5^{\mathrm{a}} \pm 0.48$ & $0^{\mathrm{a}}$ & $11.4^{\mathrm{a}} \pm 1.5$ & $26.3^{\mathrm{a}} \pm 2.4$ \\
\hline CS2 & $6.7^{\mathrm{b}} \pm 0.14$ & $0^{\mathrm{a}}$ & $0^{\mathrm{c}}$ & $14.7^{\mathrm{b}} \pm 2.1$ \\
\hline
\end{tabular}

* Means \pm standard deviation followed by the same letter/column do not differ statistically at the $95 \%$ confidence level (Tukey's test).

By adding the modified starches with a high water retention capacity, there will be a higher amount of steam available during baking for the gel to inflate and the product to expand. However, when used in excess, the product may overexpand, creating hollow spaces and damaging the final product's quality. The use of starches with low expansion properties results in a product with a dough that is compact and "chewy". In addition, the bun's crust may be dry and dark, making the product less attractive to the consumer. The combination of native and modified starches is interesting for the industry since they have distinct characteristics and, when associated, can complement the growth and standardization of cheese buns, mainly in regards to the crust as well as the bun's internal texture.

Regarding the freezing and freeze-thaw cycle of starches (Table 2) no significant difference was observed in the first one $(\mathrm{P}<0.05)$. However, differences between the starches were observed in the second and third freezing and freeze-thaw cycles, with the native starch CS2 and the modified MS2 displaying lower rates of water loss. Thus, these two starches would be better suited to be used to produce frozen cheese buns, considering their resistance to freezing and freeze-thaw cycles. The information available in the literature [27] is similar to the findings of the present study, with a trend towards greater water release percentage during the $2^{\text {nd }}$ and $3^{\text {rd }}$ cycle of freezing and freeze-thaw cycles.

In the industrial process of producing frozen cheese buns, the product is subjected to freezing. The consumer can then thaw it. At this point, it is possible that the starch retrogradation phenomenon occurs, which is characterized by water loss and fragmentation of the starch's structure, leading to undesirable modifications in the product. 


\section{Conclusions}

The native (15 and 17\% of amylose) and modified cassava starches (9,11 and 12\% of amylose) presented distinct responses for expansion properties, resistance to freezing cycles, crystallinity, granular structure, elemental constitution, and thermal behavior. Cassava starch samples with $17 \%$ of amylose had the highest expansion index among the tested samples. In contrast, the pre-gelatinized acetylated ones showed little expansion capacity. However, they presented a higher water absorption capacity, forming more viscous and compact gels. The mixing of the two types of starch resulted in a dough with high water absorption capacity, good specific volume, and a more standardized final product, since the gels formed by the pregelatinized acetylated starches tend to maintain their rounded shape during baking.

All evaluated starches displayed resistance to up to 2 freezing and thawing cycles, with the modified starch with $9 \%$ of amylose being the only one that did not show any water loss when submitted to 3 freezing and thawing cycles. The XRD analysis pointed out that the modified starches possessed similar diffraction patterns among themselves. The same was also observed with the native starches, these showing high crystallinity. SEM images revealed that modified starches possess smaller granules and greater surface area than the native starches, as well as surface indentations, which explains their greater water absorption capacity. Elemental analysis showed that carbon and oxygen are the major constituents of all starches. The presence of sodium, chlorine, calcium, and silicon was also detected in all starch samples at varying amounts. The thermal behavior of the native and modified starches presented similarities and 3 distinct stages, with MS1 presenting the lowest moisture content among the analyzed starches. There was thermal stability reduction on MS2 and MS3 starches when compared to native starches.

\section{Funding}

This study was financed by CAPES, Brazil [Financial Code 001].

\section{Acknowledgments}

The authors thank to National Council for Scientific and Technological Development (CNPq), Coordination for the Improvement of Higher Education Personnel (CAPES), and Research Support Foundation of the State of Rio Grande do Sul (FAPERGS).

\section{Conflicts of Interest}

The authors declare no conflict of interest.

\section{References}

1. Eliasson, A.C. Starch in food - Structure, function and applications. Boca Raton-CRC, Cambridge: Woodhead Pub. 2004; pp. 605.

2. Fennema, O.R.; Damodaran, S.; Parkin, K.L. Food Chemistry of Fennema. $4^{\text {th }}$ ed. Boca Raton: CRC Press, Fourth Edition. 2007; pp.1160.

3. Kaur, B.; Ariffin, F.; Bhat, R.; Karim, A.A. Progress in starch modification in the last decade. Food Hydrocoll. 2012, 26, 398-404.

4. Ahmed, S.; Zhou, X.; Pang, Y.; Xu, Y.; Tong, C.; Bao, J. Genetic diversity of potato genotypes estimated by starch physicochemical properties and microsatellite markers. Food Chem. 2018, 257, 368-375, https://doi.org/10.1016/j.foodchem.2018.03.029.

5. Khlestkin, V.; Peltek, S.; Kolchanov, N. Review of direct chemical and biochemical transformations of starch. Carbohyd Polym. 2018, 181, 460-476, https://doi.org/10.1016/j.carbpol.2017.10.035. 
6. Tappiban, P.; Ying, Y.; Pang, Y.; Sraphet, S.; Srisawad, N.; Smith, D.R.; Wu, P.; Triwitayakorn, K.; Bao, J. Gelatinization, pasting and retrogradation properties and molecular fine structure of starches from seven cassava cultivars. Int. J. Biol. Macromol. 2020, https://doi.org/10.1016/j.ijbiomac.2020.02.119.

7. Díaz, A.; Dini, C.; Viña, S.Z.; García, M.A. Technological properties of sour cassava starches: Effect of fermentation and drying processe. LWT - Food Sci. Technol. 2018, 93, 116-123, https://doi.org/10.1016/j.lwt.2018.03.029.

8. Markets, Markets. Analysis. Modified Starch Market by Raw Material (Corn, Tapioca, Potato \& Wheat), Function (Thickening, Stabilizing, Binding \& Emulsifying), Application (Food, Feed, and Non-Food), \& by Region. Global Trends\& Forecast to 2020. (accessed on 03 March 2020). https://www.marketsandmarkets.com/Market-Reports/modified-starch-market-511.

9. Tawfik, S.; Elsalam, S.H.A,; Nassar, S.H.; Sehata, I.A.; Elshemy, N.S.; El-Thalouth, A. Microwave assisted chemical modification of starch in presence or absence of amylase enzyme and its application in textile printing. Lett. Appl. NanoBioScience. 2019, 8, 762-769, https://doi.org/10.33263/LIANBS84.762769.

10. Fernandes, D.S.; Dos Santos, T.P.R.; Fernandes, A.M.; Leonel, M. Harvest time optimization leads to the production of native cassava starches with different properties. Int. J. Biol. Macromol. 2019, 132, 710-721, https://doi.org/10.1016/j.ijbiomac.2019.03.245.

11. Dudu, O.E.; Li, L.; Oyedeji, A.B.; Oyeyinka, S.A.; Ma, Y. Structural and functional characteristics of optimised dry-heat-moisture treated cassava flour and starch. Int. J. Biol. Macromol. 2019, 133, 1219-1227, https://doi.org/10.1016/j.ijbiomac.2019.04.202.

12. Sun, D.; Yoo, B. Effect of tapioca starch addition on rheological, thermal, and gelling properties of rice starch. LWT - Food Sci. Technol. 2015, 64, 205-211, http://dx.doi.org/10.1016\%2Fj.lwt.2015.05.062.

13. Tao, K.; Li, C.; Yu, W.; Gilbert, R.G.; Li, E. How amylose molecular fine structure of rice starch affects functional properties. Carbohydr. Polym. 2019, 204, 24-31, https://doi.org/10.1016/j.carbpol.2018.09.078.

14. Boonna, S.; Tongta, S. Structural transformation of crystallized debranched cassava starch during dual hydrothermal treatment in relation to enzyme digestibility. Carbohydr. Polym. 2018, 191, 1-7, https://doi.org/10.1016/j.carbpol.2018.03.006.

15. Demiate, I.M.; Dupuy, N.; Huvenne, J.P.; Cereda, M.P.; Wosiacki, G. Relationship between baking behavior of modified cassava starches and starch chemical structure determined by FTIR spectroscopy. Carbohydr. Polym. 2000, 42, 149-158, https://doi.org/10.1016/S0144-8617(99)00152-6.

16. Cereda, M.P.; Wosiacki, G. Characterisation of Pinhao Starch Part II, Rheological properties of the paste. Starch-Stärk. 1985, 37, 404-407, https://doi.org/10.1002/star.19850371203.

17. Van Soest, J.J.G.; Vliegenthart, J.F.G. Crystallinity in starch plastics: consequences for material properties. Trends Biotechnol. 1997, 15, 208-213, https://doi.org/10.1016/S0167-7799(97)01021-4.

18. Monroy, Y.; Rivero, S.; García, M.A. Microstructural and techno-functional properties of cassava starch modified by ultrasound. Ultrason. Sonochem. 2018, 42, 795-804, https://doi.org/10.1016/j.ultsonch.2017.12.048.

19. Schlemmer, D.A.; Rômulo, S.; Sales, M.J.A. Morphological and thermomechanical characterization of thermoplastic starch/montmorillonite nanocomposites. Compos. Struct. 2010, 92, 2066-2070, https://doi.org/10.1016/j.compstruct.2009.10.034.

20. Leonel, M. Alalysis of the shape and size of starch grains from different botanical species. Food Sc. Technol. 2007, 27, 579-588, https://doi.org/10.1590/S0101-20612007000300024.

21. Defloor, I.; Dehing, I.; Delcou, J. Physicochemical properties of cassava starch. Starch-Stärke 1998, 50, 5864.

22. Cereda, M.P.; Vilpoux, O.F.; Sarmento, S.B.S. General properties of starch. São Paulo, SP, Brazil: Cargill Foundation. 2001; pp. 221.

23. França, L.A.; Batista, A.C.; Viana, R.R.; Prado, R.J. Quantitative Analysis by Dispersive X-ray Spectrometry in Energy. Departamento de Física ICET UFMT. Cuiabá, Mato Grosso. 2011.

24. Guinesi, L.S.; da Róz, A.L.; Corradini, E.; Mattoso, L.H.C.; Teixeira, E.; Curvelo, A.A.S. Kinetics of thermal degradation applied to starches from different botanical origins by non-isothermal procedures. Thermochim. Acta. 2006, 447, 190-196, https://doi.org/10.1016/j.tca.2006.06.002.

25. Lawal, O.S. Succinil and acetyl starch detivatives of a hybrid maize: physicochemical characteristics and retrogration properties monitores by differencial scaning calorimetry. Carbohydr. Res. 2004, 339, 26732682, https://doi.org/10.1016/j.carres.2004.08.015.

26. Aggarwal, P.; Dollimore, D.; Heon, K. Comparative thermal analysis study of two biopolymers, starch and cellulose. J. Therm. Anal. Calorim. 1997, 50, 7-17, https://doi.org/10.1007/BF01979545.

27. Aplevicz, K.S.; Demiate, I.M. Characterization of native and modified cassava starches and use in baked goods. Food Sc. Technol. 2007, 27, 478-484, https://doi.org/10.1590/S0101-20612007000300009. 